\title{
Factors Influencing Organic Food Purchase Intention in an Emergent Market: An Empirical Investigation of Saudi Arabia
}

\author{
Eman H. Alshammari
}

\begin{abstract}
The consumption of organic food has increased owing to consumers becoming more concerned about their health. Many people have begun to realize the advantages of using organic instead of conventional food. Consumer-attitude is now the most influential factor affecting consumer purchase intention toward organic food. This study aims to identify factors influencing consumers' attitudes and purchase intention toward organic food in the Saudi context. The data used here were collected from 147 participants by using structured questionnaires. Structural equation modelling and partial least square (SmartPLS) were used to analyze the data collection. The results show that issues relating to food quality and scepticism influence consumers' attitudes toward organic food. Interestingly, organic food knowledge and health consciousness are not significant in influencing consumer attitudes toward organic food. Besides, none of the moderating effects were significant (e.g., food safety and price) regarding the relationship between consumer-attitude and purchase intention toward organic food. The results will help marketers and organic food retailers to understand better consumer's behaviour, build their marketing strategy and make advantageous decisions.
\end{abstract}

Index Terms - Behaviour, consumer attitude, organic product, purchase intention, scepticism.

\section{INTRODUCTION}

The consumption of organic food has increased owing to consumers becoming more concerned about their health. A number of studies have raised consumers' concerns about the use of pesticides within the food production process, which increasingly incline their demand for organic food purchase [27], [32]. Consumers consider organic food to be safer, tastier and comparatively more nutritious than conventional food alternatives [58]. According to [27] consumers purchase organic food despite the premium price of the products. Therefore, understanding consumer behavior toward organic food has received considerable attention from academics, government and practitioners [11].

A number of studies have been conducted regarding attitudes towards organic food products in consumerbehaviour literature. Prior researches have suggested some motivators which could influence consumers' perception toward organic food as well as health consciousness [10], [26], [37], food quality [21], [47], [57], organic food knowledge [10], [42], [60] and skepticism [18], [22], [25].

Published on December 17, 2020.

Eman H. Alshammari, Department of Business Administration, Imam Muhammad ibn Saud Islamic University, Saudi Arabia.

(e-mail: Ehshammari@imamu.edu.sa)
According to [47], quality, safety, knowledge and health were found to be important motivators in developed countries, while age, gender, income, education and health were important factors for developing countries. However, previous studies reported mixed results about the impact of motives on attitude and purchase intention towards organic products where very limited studies have been conducted in the case of Saudi Arabia [53].

Despite the fact that demand for organic food is still low in Saudi Arabia, the trend of consuming organic products is growing [52]. The results of prior researches have reported both significant and insignificant relationships [7], [10], [46], [58], [67], highlighting the need to understand the reasons behind consumers' purchasing intention toward organic products. Thus, this study aims to determine the important factors that could influence consumers' perception towards organic food, in general, and what factors motivate Saudi consumers, in particular. The results will provide guidance for marketers and organic food retailers to formulate an effective market communicationstrategy to influence consumers' behaviour toward organic food products.

\section{THEORETICAL FRAMEWORK AND HYPOTHESIS}

\section{A. Health Consciousness}

In recent years, health consciousness and concerns about well-being have become more common among consumers and are continually growing worldwide [26]. According to [37], consumers are worried about their state of health and are seeking to maintain strong constitutions by adopting healthy behaviors. Owing to changing lifestyle and eating habits, consumers are becoming more focused on healthy eating and use of appropriate diets [10]. Here, consumers tend to be more selective about their food and willing to alter their eating habits to improve their health [6]. Previous studies found that health concerns was one of the important key motivating factors for purchasing organic food among UK consumers [36], [37]. [55] observed that health-concern positively influences organic food purchase intention. In addition, health consciousness was found to predict consumers' attitudes toward organic food which, in turn, influence their purchase intention [28], [37], [62]. Even though health consciousness has a significant influence on consumers' attitudes toward organic food purchasing behavior, other studies found otherwise [10], [32]. Although consumers are currently aware of the benefits of consuming organic food, it is not necessary to translate to an actual purchase [11]. Health consciousness has therefore been seen 
as an important determinant that motivates consumers to purchase organic food. Based on the above discussion, hypothesis was generated as follows:

H1: There is a positive significant relationship between health consciousness and attitude toward organic food products.

\section{B. Food Quality}

Although health consciousness plays an important role in expanding the consumption of organic food products, consumers also seek higher food quality that does less damage to human beings and the environment [57]. According to [21], consumers' positive perceptions of organic food have increased owing to the quality of organic food being higher than that of non-organic products. Previous studies have reported that product-quality is one of the main antecedents for increasing organic food consumption [44]. An empirical study found that product quality was the most important motive for purchasing organic food among Indian consumers [11]. Other studies have also concluded that product-quality has a significant influence on consumers' attitudes toward organic food purchasing behavior [10], [21], [43]. Thus, since consumers believe that organic food products are healthier and have reliably higher quality, the more consumers would likely to buy organic food [29], [55]. However, other studies found that consumers do not believe in organic food quality [41]. Thus, product quality could be an important predictor of attitude toward organic food purchase intention, this study hypothesizes that:

$\mathrm{H} 2$ : There is a positive significant relationship between product quality and attitude toward organic food products

\section{Organic Food Knowledge}

It has been found that consumers' knowledge of organic food plays an important role in their buying decisions [42]. These refer to the levels of awareness that consumers acquire about organic products' attributes [45]. Prior knowledge of organic products has an effect on consumer attitudes toward consumption of organic food [19]. Past studies supported that knowledge of organic food influences consumer attitudes toward organic food which, in turn, affect their purchase intention [17], [42], [60]. Other studies have confirmed that purchase intention was positively influenced by consumers' knowledge of organic food [60], [61], [66]. According to [67], the lack of organic knowledge acts as a barrier to organic food purchase intention whereas the increase of organic knowledge enhances organic food consumption. This means the higher perceived knowledge of organic food, the higher considering organic food in their choices occurs [16]. Thus, based on the above discussion, this study advances the following hypothesis:

H3: There is a positive relationship between organic food knowledge and attitude toward organic food products.

\section{Consumer Scepticism}

Consumer scepticism refers to the general tendency that creates doubt of green products labelling [18]. It has been defined that sceptical consumers are those who disbelieve the information on food product labels [39]. According to [25] the level of consumer scepticism acts as an obstacle to organic food purchase. Previous studies found that scepticism has a negative influence on green products purchasing behaviour [40]. Other studies found that consumer scepticism did not influence consumers' purchase decisions [22]. On the other hand, other studies demonstrated that consumers were less sceptical toward health labels than the hedonic [18]. Thus, consumer scepticism may influence consumers' evaluation of food labels and increase complexity of their decision purchase. Therefore, there are very few studies that examined the effect of scepticism toward organic food labelling. This study contributes towards the understanding of the relationship between consumer scepticism and consumer attitudes toward organic food purchasing intention. Therefore, this study hypothesizes the following:

H4: There is a negative relationship between consumer scepticism and consumer attitude toward organic food products

\section{E. Attitude}

Consumer's attitude is an important antecedent for predicting consumers' purchase intention across products and services, including organic food [65]. [3] defines attitude as individual's expression of favourable or unfavourable evaluation to perform a given behaviour. Theory of planned behaviour (TPB) proposed that behavioural intention is predicted by attitude toward the behaviour [2]. TBP has been widely examined and successfully applied in different subjects to explain human behavior [2], [3]. Although TPB is a well-known framework in business researches, marketing researchers have also used TBP to understand consumers' behaviour towards organic food consumption [1], [15], [49], [68]. Past studies found a significant positive relationship between attitude and consumer behaviour toward organic products [42], [49], [65]. In addition, [50] attitude has a major role in shaping consumers' intention toward organic food. According to [4], the more favourable the attitude toward organic food, the greater the behavioural intention to perform the behaviour. Therefore, attitude can be considered as an important role in predicting consumers behaviour. Thus, the following hypothesis proposed:

H5: There is a positive relationship between attitude and consumer purchase intention towards organic food products.

\section{F. The Moderating Role of Price}

Price has been recognized as a key factor influencing consumers' purchase decisions [8]. According to [67] price is one of the main barriers that discourage consumers from demanding organic products. This suggests that consumers use price as an important determinant for their purchase. In addition, [42] proved that there is a negative relationship between price and consumer attitude toward buying organic food. This means that consumers negatively perceive organic food premium price compared to conventional food which, in turn, affects their attitudes toward organic food. Other studies found no significant relationship between price and consumer attitude toward organic food [54]. However, [38] argue that despite consumers being aware of organic food premium costs, they accept high prices. In contrast, [35] reported that organic food prices should not exceed conventional ones. This suggests that organic food 
retailers need to clarify the monetary value that consumers will gain from purchasing organic food. [54] suggest that consumers might be more inclined to buy organic food once prices have decreased. Therefore, since price may affect the relationship between attitude and purchase intention, this study hypothesis that:

H6: Price moderated the relationship between attitude and purchase intention toward organic food.

\section{G. The Moderating Role of Food Safety Concern}

Food safety refers to consumers' concerns about contracting diseases caused by artificial additives, fertilizers, and chemical sprays of non-organically produced products [11]. Consumers believe that organic food products present less risks and harmful pesticide content than conventional food products [37]. Owing to multiplying concerns about food quality and safety, the demand for organic food has also increased [63]. According to [45], food safety is one of the key factors driving the purchase of organic food. Previous studies found that food safety is a significant predictor of consumer-attitude toward organic food [31], [37], [45], [62], [64]. Although most studies identify food safety as a reason for the purchase of organic food, a few have found otherwise. For example, [11] found that food safety concerns did not predict consumers' attitudes toward buying organic food owing to Indian consumers' disbelief in the opinion that organic food could allay their safety concerns. Therefore, because the literature shows mixed results regarding the importance of food safety about favouring or disfavouring organic food products, this study explores the role of safety concern as a moderating variable on the relationship between consumer attitude and purchase intention. Thus, the study hypothesized that:

H7: Safety concern moderated the relationship between attitude and purchase intention toward organic food.

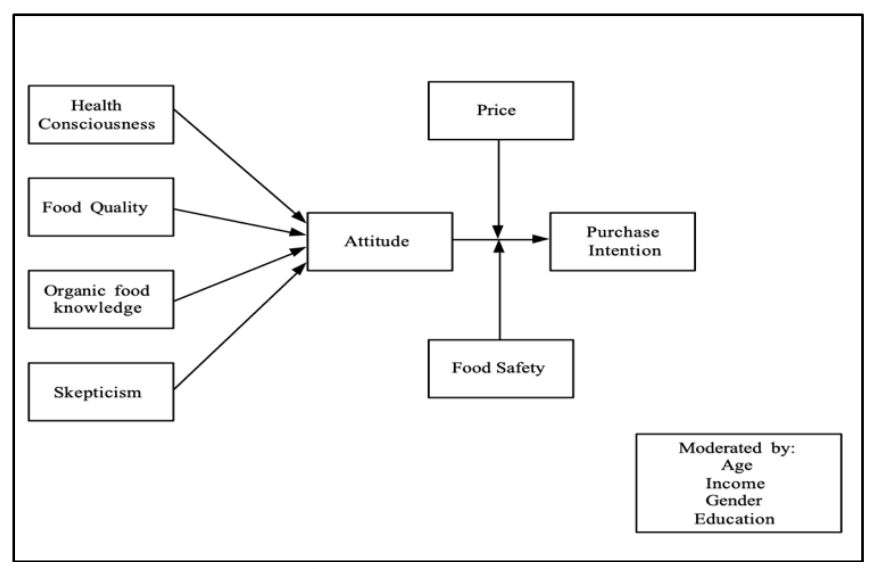

Fig 1. Conceptual Model

\section{RESEARCH MEthodology}

\section{A. Measurement of the Variables}

The items of each construct were adopted from previous studies using seven Likert scale response categories where $(1=$ strongly disagree and $7=$ strongly agree $)$. Health consciousness was measured by four items developed by [20]. Five items developed by [27] were used to measure food quality. In addition, three items were used to measure food safety which adopted from [48]. Another four items were adopted from [42] to measure organic food knowledge. Attitude (four items) and intention (four items) were adopted from [2] [3]. Price was measured using five items adopted from [42]. Finally, scepticism was measured by using nine items adopted from [18].

\section{B. Sample and procedure}

The questionnaire was examined through pilot study to ensure the validity and reliability of all response items. A self-administrated questionnaire (primarily with closed questions) was conducted to collect data from a nonprobability sampling approach by using the convenience sampling method. The survey was distributed to consumers in Riyadh, the capital city of Saudi Arabia. Within the total of 219 questionnaires, only 147 responses were fully completed and usable for further data analysis, with a response rate of 67 per cent. The questionnaire was divided into two parts: the first consisted of questions designed to evaluate factors that influence consumers' attitude toward organic food purchase intention as well as health consciousness, food safety, product quality, price, organic food knowledge and consumer scepticism, where the second part enquires some demographic data of the respondents.

\section{RESEARCH RESULTS}

\section{A. Descriptive analysis}

Preliminary data analysis was conducted prior to application of Smarts-SEM in order to ensure that the dataset was ready for further analysis. The result indicates that about $53 \%$ of the respondents were females while the remaining $47 \%$ were males. The majority of respondents were aged between 25 and 44, which accounts for around $69 \%$ of sample respondents. The majority of respondents $(51 \%)$ were graduates followed by postgraduates $(28 \%)$ and those pursuing doctoral studies (12\%). The results also indicate that $29 \%$ of respondents earned a salary of SR 3000 or less, followed by $15 \%$ earning between SR 12001 and SR 15000 while $12 \%$ received between SR 6001 to SR 9000. A further $12 \%$ got a salary of between 15001 and SR 18000 and $9 \%$ earned 24000 and above, closely followed by $8 \%$, who were getting between SR 9001 and SR 12000. Number of respondents (6\%) had an income of SR 18001 to SR 21000 where $5 \%$ and $4 \%$ earned SR 21001 to 24000 and SR 3001 to SR 6000 respectively (see Table 1).

\section{B. Common Method Biased (CMB)}

CMB was assessed through using Harman's single-factor method, which checks if a single common factor accounts for most of the variance across all the factors. The single factor of $50 \%$ or higher of variance indicates the presence of CMB. Thus, the results show that the first factor has explained only $28.022 \%$, which suggests that CMB is not a concern in this study. 
TABLE 1: SOCIO-DEMOGRAPHIC PROFILE OF RESPONDENTS

\begin{tabular}{|c|c|c|}
\hline Characteristic & Frequency & $\%$ \\
\hline \multicolumn{3}{|l|}{ Gender } \\
\hline Male & 69 & 46.9 \\
\hline Female & 78 & 53.1 \\
\hline Total & 147 & 100 \\
\hline \multicolumn{3}{|l|}{ Age } \\
\hline $18-24$ & 18 & 12.2 \\
\hline $25-34$ & 41 & 27.9 \\
\hline $35-44$ & 60 & 40.8 \\
\hline $45-54$ & 19 & 12.9 \\
\hline $55-64$ & 8 & 5.4 \\
\hline $65+$ & 1 & 0.8 \\
\hline Total & 147 & 100 \\
\hline \multicolumn{3}{|l|}{ Education } \\
\hline High School qualification & 14 & 9.5 \\
\hline Bachelor's degree & 75 & 51.0 \\
\hline Master's degree & 40 & 27.2 \\
\hline Doctoral degree & 18 & 12.2 \\
\hline Total & 147 & 100 \\
\hline \multicolumn{3}{|l|}{ Income } \\
\hline 3000 or Less & 43 & 29.3 \\
\hline $3001-6000$ & 6 & 4.1 \\
\hline $6001-9000$ & 17 & 11.6 \\
\hline $9001-12000$ & 12 & 8.2 \\
\hline $12001-15000$ & 22 & 15.0 \\
\hline $15001-18000$ & 17 & 11.6 \\
\hline $18001-21000$ & 9 & 6.1 \\
\hline $21001-24000$ & 7 & 4.8 \\
\hline Over 24000 & 14 & 9.5 \\
\hline Total & 147 & 100 \\
\hline
\end{tabular}

\section{Assessment of Measurement Model}

As suggested by [23], PLS was utilized through two stages of data analysis, the measurement model and structural model as shown on Fig. 2. The assessment of measurement model initially focuses on evaluating the indicator reliability, internal consistency reliability, convergent validity and discriminant validity (Table 2), whereas the structural model focuses on hypothesis testing [23]. The assessment of a reflective measurement model comprised three criteria: internal consistency, convergent validity and discriminant validity [23]. Internal consistency involves Cronbach's alpha and composite reliability tests to assess the consistency of the measures [23]. Convergent validity analysis includes the average variance extracted (AVE) and composite reliability (CR). Most of the outer loadings of the eight constructs are above the suggested value of 0.70 , which indicate sufficient level of indicator reliability. However, a number of items (QUL1; PRC4; PRC5; SCPT1and SCPT8) were deleted because they did not meet the suggested value of 0.6 [23]. Yet, indicators with outer loading ranges from 0.40 to 0.70 should be removed only if it leads to an increase in CR or AVE [23]. The reliability of constructs was inspected by using Cronbach's alpha and CR, where the results of all constructs exceeded the suggested value of 0.70 , representing strong reliability. Further to this, convergent validity was achieved using AVE, whereby results suggest that all constructs were above the threshold value of 0.50 [23].

Furthermore, discriminate validity was assessed through using the Fornell-Larcker (1981) [23] criterion. According to [23], discriminate validity is established when the square root of each construct's AVE is greater than its correlation with another construct and each loading of indicators highest on its associated construct [23]. Thus, the results in Table 3 show that discriminate validity was established.

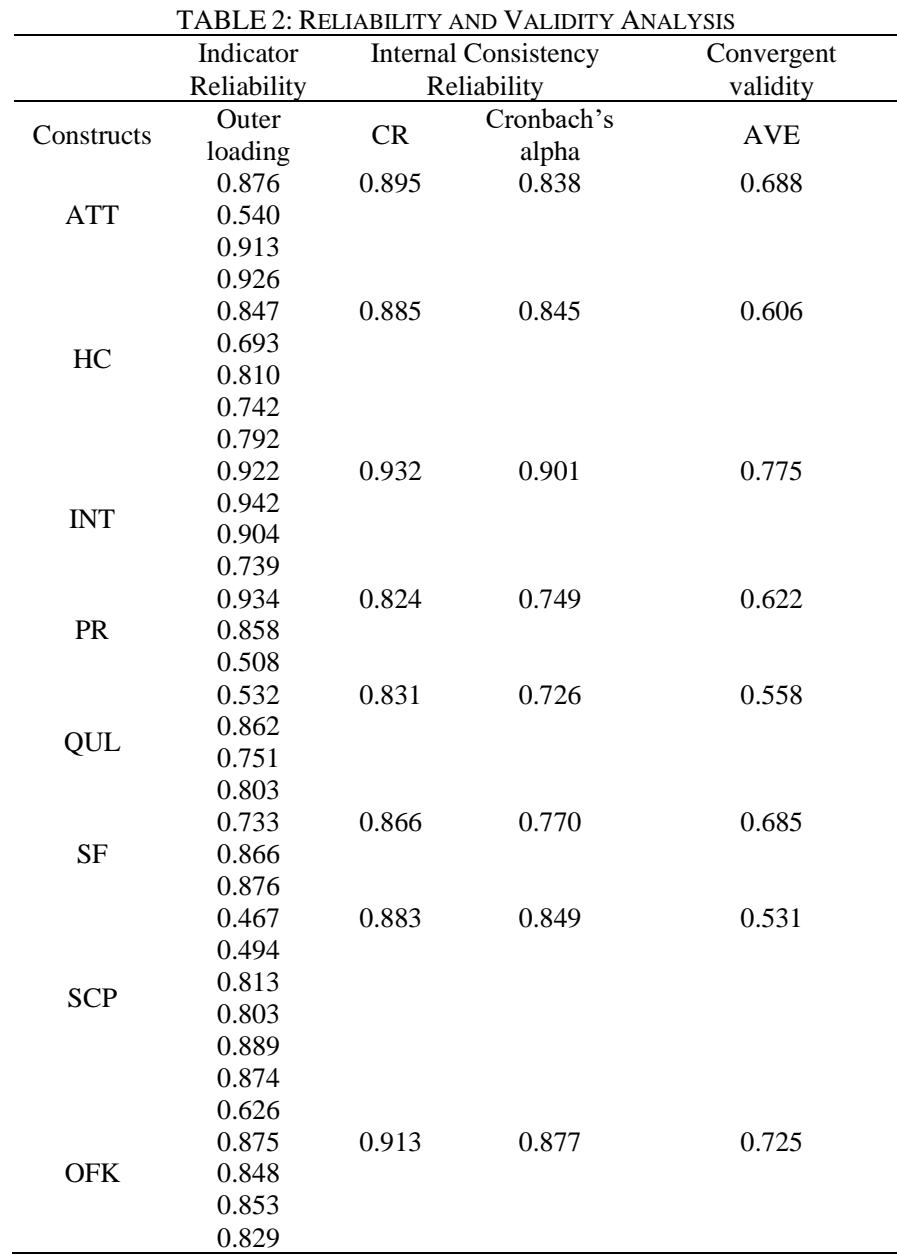

Note: $\mathrm{AVE}=$ Average variance extracted; $\mathrm{CR}=$ Composite reliability; $\mathrm{ATT}=$ attitude $\mathrm{HC}=$ Health consciousness; $\mathrm{INT}=$ Intention; $\mathrm{PR}=$ Price; $\mathrm{QUL}=$ Quality; SF= Safety; SCP= Scepticism; OFK= Organic food knowledge.

\begin{tabular}{ccccccccc}
\multicolumn{8}{c}{ TABLE 3. THE FORNELL-LARCKER RESULT } \\
\hline \multicolumn{1}{c}{ ATT } & OFK & HC & INT & PR & QUL & SF & SCP \\
\hline ATT & 0.829 & & & & & & & \\
OFK & 0.458 & 0.851 & & & & & & \\
HC & 0.420 & 0.580 & 0.779 & & & & & \\
INT & 0.687 & 0.442 & 0.328 & 0.880 & & & & \\
PR & 0.252 & 0.194 & 0.176 & 0.212 & 0.789 & & & \\
QUL & 0.627 & 0.518 & 0.542 & 0.384 & 0.153 & 0.747 & & \\
SF & 0.488 & 0.425 & 0.403 & 0.398 & 0.239 & 0.470 & 0.828 & \\
SCP & -0.48 & -0.40 & -0.29 & -0.34 & -0.20 & -0.54 & -0.24 & 0.729 \\
\hline
\end{tabular}

Note: values in bold are the square root of the AVE; ATT = attitude; $\mathrm{HC}=$ Health consciousness; INT $=$ Intention; $P R=$ Price; $Q U L=$ Quality; $S F=$ Safety; SCP= Scepticism; OFK= Organic food knowledge.

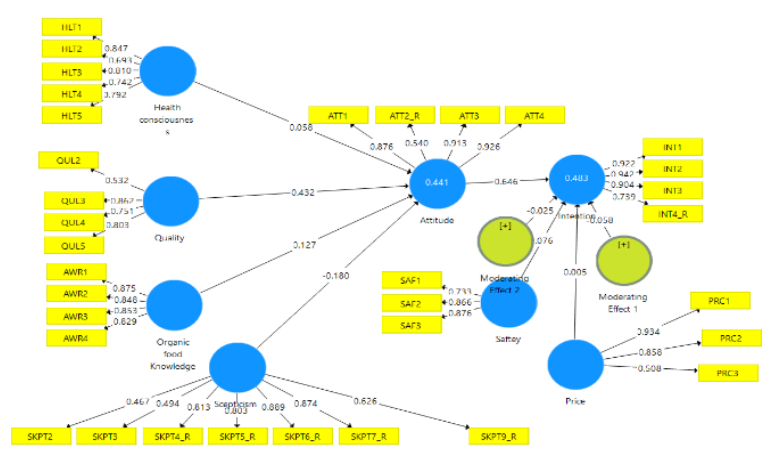

Fig. 2. Path Model Results (Algorithm).

\section{Assessment of Structural Model}

After ensuring the reliability and validity of the measurement model, the next step is evaluating the 
structural model in order to assess it for collinearity issues (VIF), Path coefficients $\beta$ and the corresponding of t-values, the level of $R^{2}$, effect size $f^{2}$ and predictive relevance $\mathrm{Q}^{2}$ [23]. Table 4 shows that all the VIF values of the endogenous and exogenous constructs were clearly below the threshold value of 5 , representing no critical issue of the collinearity among the constructs. The $R^{2}$ of attitude was 0.441 , indicating that all the predictors explained 44 per cent of the variance in attitude, whereas the $R^{2}$ of Intention was 0.483 , demonstrating that attitude explained 48 per cent of the variance in intention (see Table 6).

\begin{tabular}{|c|c|c|c|c|c|c|c|c|}
\hline & ATT & OFK & $\mathrm{HC}$ & INT & PR & QUL & SF & SCP \\
\hline ATT & & & & 1.359 & & & & \\
\hline OFK & 1.716 & & & & & & & \\
\hline $\mathrm{HC}$ & 1.724 & & & & & & & \\
\hline INT & & & & & & & & \\
\hline PR & & & & 1.288 & & & & \\
\hline QUL & 1.887 & & & & & & & \\
\hline SF & & & & 1.530 & & & & \\
\hline SCP & 1.466 & & & & & & & \\
\hline
\end{tabular}

Note $: \mathrm{ATT}=$ attitude; $\mathrm{HC}=$ Health consciousness; $\mathrm{INT}=$ Intention; $\mathrm{PR}=$ Price; $\mathrm{QUL}=$ Quality; $\mathrm{SF}=$ Safety; $\mathrm{SCP}=$ Scepticism; $\mathrm{OFK}=$ Organic food knowledge.

For the path coefficients assessments, Fig. 3 shows that only three out of seven hypotheses were supported. Table 5 shows that health consciousness $(\beta=0.058, p=0.428)$ and organic food knowledge $(\beta=0.127, p=0.100)$ were positively related to attitude but not significant, resulting in H1 and H3 being not supported. Further, food quality $(\beta=$ $0.432, p<0.01)$ and scepticism $(\beta=-0.180, p<0.05)$ were significantly influenced by attitude, presenting $\mathrm{H} 2$ and $\mathrm{H} 4$ as supported. Attitude toward organic positively influenced by consumer purchase intention at the significance level of $\mathrm{p}<0.01$, indicating H5 supported.

Recall that H6 predicted that price will moderate the relationship between attitude and purchase intention toward organic food, such that this relationship will be weaker when price is high than when it is low. The result shows that there was no significant interaction effect between attitude and purchase intention $(\beta=-0.058, p=0.552)$. Thus, hypothesis 6 was not supported. Another moderator variable was examined to predict the effect of safety on the relationship between attitude and purchase intention as the attitude is stronger when the customer perceived safety of organic product; thus, will be more likely to purchase. However, safety did not moderate the relationship between attitude and purchase intention $(\beta=0.025, \mathrm{P}=0.815)$ and therefore $\mathrm{H} 7$ was not supported.

TABLE 5: PATH COEFFICIENTS AND HYPOTHESIS TESTING

\begin{tabular}{cccc}
\hline Path Relationships & $\begin{array}{c}\text { Path } \\
\text { Coefficients }\end{array}$ & t-values & P-values \\
\hline $\begin{array}{c}\text { Attitude -> Intention } \\
\text { Organic food knowledge -> } \\
\text { Attitude }\end{array}$ & 0.646 & $7.804 * *$ & 0.000 \\
Health consciousness -> & 0.127 & 1.643 & 0.100 \\
Attitude & 0.058 & 0.792 & 0.428 \\
Moderating Effect 1 -> Intention & -0.058 & 0.595 & 0.552 \\
Moderating Effect 2 -> Intention & -0.025 & 0.234 & 0.815 \\
Price -> Intention & 0.005 & 0.066 & 0.947 \\
Quality -> Attitude & 0.432 & $4.098 * *$ & 0.000 \\
Safety -> Intention & 0.076 & 0.838 & 0.402 \\
Scepticism -> Attitude & -0.180 & $2.098 *$ & 0.036 \\
\hline Note: $*$ p <.05; * p <.01; *** p <.001. & &
\end{tabular}

In addition, Stone-Geisser was applied in order to test predictive relevance $\left(\mathrm{Q}^{2}\right)$ by using blindfolding procedures [23]. According to [23] [24] $\mathrm{Q}_{2}$ values higher than zero indicate that the model's predictive relevance for a particular latent variable is established. The result revealed that $\mathrm{Q}^{2}$ value for endogenous latent variable were above zero for Attitude 0.291 and intention 0.339, suggesting predictive relevance of the model [23].

\begin{tabular}{ccc} 
TABLE 6: PREDICTIVE RELEVANCE AND R2 RESULTS \\
\cline { 2 - 3 } Construct & $\mathrm{Q}^{2}$ & $\mathrm{R}^{2}$ \\
\hline Attitude & 0.291 & 0.441 \\
Intention & 0.339 & 0.483 \\
\hline
\end{tabular}

Furthermore, [23] suggested that effect size $f^{2}$ assesses the structural model after a change in the $\mathrm{R}^{2}$ when a particular exogenous variable is omitted from the model, and whether or not this omitted construct has a substantive effect on the endogenous construct [23]. According to Cohen (1988), $f^{2}$ values of $0.02,0.15$ and 0.35 , indicating small, medium and large effects. Table 7 shows that organic food knowledge has a small effect size of 0.031 on attitude, while price has a small effect size of 0.036 on purchase intention. Scepticism and safety have a medium effect size on attitude with 0.161 and 0.128 , respectively. A large effect size of attitude was found on purchase intention (0.453), while no effect sizes were found of health consciousness on attitude (0.009) and food quality on purchase intention (0.002).

TABLE 7: EFFECT SIZE RESULTS

\begin{tabular}{|c|c|c|c|c|c|c|c|c|}
\hline & ATT & $\mathrm{HC}$ & INT & QUL & SF & SCP & OFK & PR \\
\hline ATT & & & 0.453 & & & & & \\
\hline $\mathrm{HC}$ & 0.009 & & & & & & & \\
\hline INT & & & & & & & & \\
\hline QUL & & & 0.002 & & & & & \\
\hline SF & 0.128 & & & & & & & \\
\hline SCP & 0.161 & & & & & & & \\
\hline OFK & 0.031 & & & & & & & \\
\hline PR & & & 0.036 & & & & & \\
\hline
\end{tabular}

Note $: \mathrm{ATT}=$ attitude; $\mathrm{HC}=$ Health consciousness; $\mathrm{INT}=$ Intention; $\mathrm{PR}=$ Price; $\mathrm{QUL}=$ Quality; $\mathrm{SF}=$ Safety $\mathrm{SCP}=$ Scepticism; OFK= Organic food knowledge.

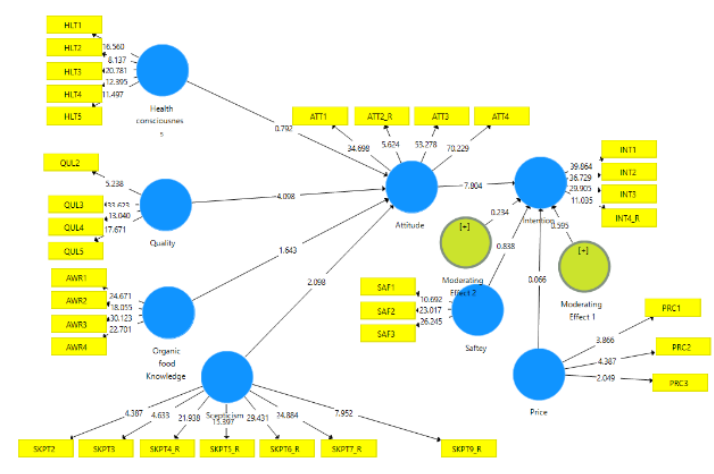

Fig. 3. Structural Model Results.

\section{E. Multigroup Analysis (MGA)}

It has been suggested that demographic variables such as age, gender, income and education have an important role in influencing consumer behaviour [25]. These variables become more critical in the marketing literature to facilitate understanding of how consumers' behaviour is influenced by their characteristics. According to [51], demographic variables may define organic food consumers, but the 
correlations were not significant. Multigroup analysis (MGA) was used to examine the interaction of demographic variables on all the path relationship in the model. However, before proceeding to perform the MGA, it becomes necessary to test the measurement invariance of composite model (MICOM).

There are three steps to assessing the MICOM test. Step one establishes the configuration invariance that automatically sets up for each group through the SmartPLS software 3.0, whereas step two assesses permutation-centred confidence intervals $(c)$ for the compositional invariance that allows determination of whether the $c$ value in Group 1 and Group 2 is significantly less than one. Step three is examined by the permutation-based confidence intervals for the mean values and the variances that allow one to assess if a value of the composite's mean and variance differs across groups. Therefore, determining these results is important to discover whether a partial or full measurement invariance has been established [24]. The results of MICOM shows that all the demographic variables except education, such as age, gender and income were partially established due to composite being formed differently across groups; thus, step two was not established.

Once the MICOM results indicated partial measurement invariance for all of the groups, the MGA was conducted to test the moderating effect of gender, age and income on all of the structural relationships. Bootstrapping was applied to assess the significance of the hypothesized relationships for each group. To ensure the statistical significance differences between groups on the proposed hypotheses, PLS-MGA test was examined [24]. Therefore, the MGA results revealed that gender was only significant on the relationship between attitude and intention to purchase organic food products $(\mathrm{p}<$ $0.05)$. It also shows that gender was significant on the relationship between safety and purchase intention $(\mathrm{p}<0.05)$. However, none of the remaining demographic variables, as well as age and income, had a moderating effect on the proposed hypotheses.

\section{DISCUSSION}

The findings of this study indicate that food quality tend to influence consumer attitudes which, in turn, affect intention to purchase organic food products. This result is supported by previous studies that found food quality positively influences consumer's attitudes toward organic food [1], [10], [21], [43], [44]. According to [5], Saudi consumers consider food quality as an important aspect in determining their behavioural intention prior to their decision-making. This finding is in line with [37], who found that consumers perceived organic food products to be of good quality - tastier and fresher than conventional food products.

This study found that scepticism regarding organic labels tends to negatively influence consumer attitude toward organic food products. This result is consistent with findings of some previous studies, which stated that consumers have a negative attitude toward organic food products owing to lack of trust relating to nutritional information on organic food labels [14], [22], [39]. However, other studies - for example, [22] - found otherwise: consumers made their buying decisions based on products' attributes and scepticism was not relevant to their choices.

In addition, the result shows that health consciousness did not influence consumer's attitudes toward organic food products. This means health consciousness did not develop favorable attitude towards enhancing health through consumption of organic food products among Saudi consumers. This may be attributed to lack of information, lack of marketing advertisement and products availability on the markets which affect their consumption of organic food [52]. Thus, the finding is consistent with previous studies which found that health consciousness did not show a significant influence on attitudes toward organic food [13].

Although it has been argued that knowledge awareness of organic food products is essential to consumers' buying decisions, the results in this study suggest otherwise. It shows that organic food knowledge awareness did not affect consumer attitudes. This means that Saudi consumers do not consider knowledge awareness of organic food as an important factor when they make their purchase decisions. According to [5], lack of knowledge was the main reason to prevent Saudi consumers from buying organic food. The finding is in line with [68], who stated that organic food knowledge didn't influence consumers' attitudes and intention toward organic food products where this result is not consistent with previous studies, which suggest a positive relationship between organic food knowledge and consumer attitude [1], [53].

In addition, this study found that attitude significantly influences purchase intention toward organic food products, which is consistent with previous studies' findings [10], [13], [53]. This suggests that the more favourable the attitude toward organic food, the more consumers are willing to purchase the products [33]. In this study, food quality and scepticism combined were found to be an important component that influences consumer attitudes and purchase intention toward organic products in Saudi Arabia.

Although it has been claimed that Japanese consumers are willing to pay $10 \%$ price premium for organic food products compared to what they will pay for conventional products [30], this study found otherwise. It shows that the impact of price effect on the relationship between attitude and purchase intention toward organic products was not significant. This means that Saudi consumers do not consider the price of organic food products to be important. Thus, the finding is consistent with [34]. However, the result is not consistent with previous studies that suggest price is perceived to be a barrier to purchase [8], [51]. Furthermore, the results show that the impact of food safety on the relationship between attitude and purchase intention was insignificant. This finding is in line with the views of prior researchers who found the alleged effect of food safety on consumer purchase intention toward organic food [12], [64] to be unclear. This also suggests that Saudi consumers do not consider safety concerns to be an important factor when they purchase organic food products. 


\section{CONCLUSION AND MANAGERIAL IMPLICATION}

The main objective of this study is to examine factors which affect consumers' purchase intention toward organic food in an emergent market such as Saudi Arabia. Based on the conclusions reached in prior studies, consumers' perceptions of organic food vary across countries [27]. The findings of this study shed some insights into organic product-producers' retailers and marketers to increase marketing campaigns that would enhance consumers' knowledge of organic food. Based on these results, it may be argued that organic food companies need to understand the factors that influence consumers' attitudes toward organic food, which might encourage consumers' intention to purchase. The findings of this study contribute to the literature that suggests purchase intention is highly predicted by food quality and scepticism among Arab consumers, specifically in Saudi Arabia. Therefore, practitioners could use the results to develop an appropriate marketing strategy that could lead to greater consideration of consumer segments and increase awareness of organic food. Further, the research may improve government policy by providing a better market analysis of patterns of consumer buying behaviour in emergent markets and may need to be adopted to support farmers in order to increase the amount of organic vegetables to maintain health and promote environmental sustainability.

\section{LIMITATION AND FUTURE RESEARCHES}

Although the present research contributes positively by filling a gap in the marketing literature in the context of a large emerging market in Arab and Muslim countries, it will not be without limitations. These limitations point to areas that need to be considered in future research. Two factors, such as health consciousness and knowledge of organic food, were deemed insignificant, thus suggesting that future studies need also to examine these factors in different contexts. There may be other factors affecting consumer attitudes toward organic food besides health consciousness, knowledge, food quality, scepticism and demographic variables. Thus, future studies may incorporate other factors which may influence consumer intention toward organic products, such as taste, animosity, advertisement and product availability. In addition, the study was conducted in Saudi Arabia with a sample size of 147 consumers that may not be sufficient to generalize the results. Therefore, future studies need to be conducted using higher sample sizes in order to reinforce the validity of the results.

\section{REFERENCES}

[1] Aertsens, J., Mondelaers, K., Verbeke, W., Buysse, J., \& Van Huylenbroeck, G. (2011). The influence of subjective and objective knowledge on attitude, motivations and consumption of organic food. British food journal.

[2] Ajzen, I. (1985). From intentions to actions: A theory of planned behavior. In Action control (pp. 11-39): Springer.

[3] Ajzen, I. (1991). The theory of planned behavior. Organizational behavior and human decision processes, 50(2), 179-211.

[4] Alam, S. S., \& Sayuti, N. M. (2011). Applying the Theory of Planned Behavior (TPB) in halal food purchasing. International journal of Commerce and Management.

[5] Almohaimmeed, B. M. (2017). Restaurant quality and customer satisfaction. International Review of Management and Marketing, $7(3)$.
[6] Apaolaza, V., Hartmann, P., D'Souza, C., \& López, C. M. (2018) Eat organic-Feel good? The relationship between organic food consumption, health concern and subjective wellbeing. Food Quality and Preference, 63, 51-62.

[7] Ariffin, S. K., Dihanan, N. N., \& Wahid, N. A. (2019). Investigating the Factors Affecting Consumer Purchase Intention towards Halal Organic Food. Journal of Entrepreneurship, Business and Economics, 7(2), 162-188.

[8] Aschemann-Witzel, J., \& Zielke, S. (2017). Can't buy me green? A review of consumer perceptions of and behavior toward the price of organic food. Journal of Consumer Affairs, 51(1), 211-251.

[9] Azjen, I. (1980). Understanding attitudes and predicting social behavior. Englewood Cliffs.

[10] Basha, M. B., \& Lal, D. (2019). Indian consumers' attitudes towards purchasing organically produced foods: An empirical study. Journal of cleaner production, 215, 99-111.

[11] Basha, M. B., Mason, C., Shamsudin, M. F., Hussain, H. I., \& Salem, M. A. (2015). Consumers attitude towards organic food. Procedia Economics and Finance, 31, 444-452.

[12] Canavari, M., Bazzani, G. M., Spadoni, R., \& Regazzi, D. (2002). Food safety and organic fruit demand in Italy: a survey. British food journal.

[13] Cheung, R., Lau, M. M., \& Lam, A. Y. (2015). Factors affecting consumer attitude towards organic food: An empirical study in Hong Kong. Journal of Global Scholars of Marketing Science, 25(3), 216-231.

[14] Činjarević, M., Agić, E., \& Peštek, A. (2018). When Consumers are in Doubt, You Better Watch Out! The Moderating Role of Consumer Skepticism and Subjective Knowledge in the Context of Organic Food Consumption. Zagreb International Review of Economics \& Business, 21(SCI), 1-14.

[15] Dangi, N., Narula, S. A., \& Gupta, S. K. (2020). Influences on purchase intentions of organic food consumers in an emerging economy. Journal of Asia Business Studies.

[16] Demirtas, B. (2019). Assessment of the impacts of the consumers' awareness of organic food on consumption behavior. Food Science and Technology, 39(4), 881-888.

[17] Díaz, F. J. M., Pleite, F. M. C., Paz, J. M. M., \& García, P. G. (2012). Consumer knowledge, consumption, and willingness to pay for organic tomatoes. British food journal.

[18] Fenko, A., Kersten, L., \& Bialkova, S. (2016). Overcoming consumer scepticism toward food labels: The role of multisensory experience. Food Quality and Preference, 48, 81-92.

[19] Gad Mohsen, M., \& Dacko, S. (2013). An extension of the benefit segmentation base for the consumption of organic foods: A time perspective. Journal of Marketing Management, 29(15-16), 17011728 .

[20] Gould, S. J. (1988). Consumer attitudes toward health and health care: A differential perspective. Journal of Consumer Affairs, 22(1), 96-118.

[21] Gracia Royo, A., \& de-Magistris, T. (2007). Organic food product purchase behaviour: a pilot study for urban consumers in the South of Italy.

[22] Guilabert, M., \& Wood, J. A. (2012). USDA certification of food as organic: An investigation of consumer beliefs about the health benefits of organic food. Journal of food products marketing, 18(5), 353-368.

[23] Hair, J., Hult, T., Ringle, C., \& Sarstedt, M. (2016). A primer on partial least squares structural equation modeling (PLS-SEM).

[24] Henseler, J., Ringle, C. M., \& Sarstedt, M. (2016). Testing measurement invariance of composites using partial least squares. International Marketing Review, 33(3), 405-431.

[25] Hughner, R. S., McDonagh, P., Prothero, A., Shultz, C. J., \& Stanton, J. (2007). Who are organic food consumers? A compilation and review of why people purchase organic food. Journal of Consumer Behaviour: An International Research Review, 6(2-3), 94-110.

[26] Hussain, T., \& Safdar, N. F. (2019). For Better or for Worse: Organic Versus Conventional Foods. EC Nutrition, 14, 493-494.

[27] Jaafar, S. N., Lalp, P. E., \& Naba, M. M. (2012). Consumers' perceptions, attitudes and purchase intention towards private label food products in Malaysia. Asian Journal of Business and Management Sciences, 2(8), 73-90.

[28] Jeong, E., \& Jang, S. S. (2019). Price premiums for organic menus at restaurants: What is an acceptable level? International Journal of Hospitality Management, 77, 117-127.

[29] Kahl, J., Baars, T., Bügel, S., Busscher, N., Huber, M., Kusche, D., Taupier-Letage, B. (2012). Organic food quality: a framework for concept, definition and evaluation from the European perspective. Journal of the Science of Food and Agriculture, 92(14), 2760-2765. 
[30] Kim, R., Suwunnamek, O., \& Toyoda, T. (2008). Consumer attitude towards organic labeling schemes in Japan. Journal of International Food \& Agribusiness Marketing, 20(3), 55-71.

[31] Krystallis, A., \& Chryssohoidis, G. (2005). Consumers' willingness to pay for organic food: Factors that affect it and variation per organic product type. British food journal, 107(5), 320-343.

[32] Kushwah, S., Dhir, A., Sagar, M., \& Gupta, B. (2019). Determinants of organic food consumption. A systematic literature review on motives and barriers. Appetite, 143, 104402.

[33] Lian, S. B. (2017). What motivates consumers to purchase organic food in Malaysia. Asian Social Science, 13(9), 100-109.

[34] Liang, R.-D. (2016). Predicting intentions to purchase organic food: the moderating effects of organic food prices. British food journal.

[35] Magnusson, M. K., Arvola, A., Hursti, U. K. K., Åberg, L., \& Sjödén, P. O. (2001). Attitudes towards organic foods among Swedish consumers. British food journal.

[36] Makatouni, A. (2002). What motivates consumers to buy organic food in the UK? Results from a qualitative study. British food journal, 104(3/4/5), 345-352.

[37] Michaelidou, N., \& Hassan, L. M. (2008). The role of health consciousness, food safety concern and ethical identity on attitudes and intentions towards organic food. International journal of consumer studies, 32(2), 163-170.

[38] Minbashrazgah, M. M., Maleki, F., \& Torabi, M. (2017). Green chicken purchase behavior: the moderating role of price transparency. Management of Environmental Quality: An International Journal.

[39] Moorman, C. (1996). A quasi experiment to assess the consumer and informational determinants of nutrition information processing activities: The case of the nutrition labeling and education act. Journal of Public Policy \& Marketing, 15(1), 28-44.

[40] Moutinho, L., Albayrak, T., Caber, M., \& Herstein, R. (2011). The influence of skepticism on green purchase behaviour. International of Business and Social Sciences, 2(13), 189-197.

[41] Naspetti, S., \& Zanoli, R. (2009). Organic food quality and safety perception throughout Europe. Journal of food products marketing, 15(3), 249-266.

[42] Nguyen, H. V., Nguyen, N., Nguyen, B. K., Lobo, A., \& Vu, P. A. (2019). Organic food purchases in an emerging market: The influence of consumers' personal factors and green marketing practices of food stores. International journal of environmental research and public health, 16(6), 1037.

[43] Paul, J., \& Rana, J. (2012a). Consumer behavior and purchase intention for organic food. Journal of consumer Marketing, 29(6), 412-422.

[44] Perera, C. R., Johnson, L. W., \& Hewege, C. R. (2018). A review of organic food consumption from a sustainability perspective and future research directions. International Journal of Management and Sustainability, 7(4), 204-214.

[45] Pham, T. H., Nguyen, T. N., Phan, T. T. H., \& Nguyen, N. T. (2018). Evaluating the purchase behaviour of organic food by young consumers in an emerging market economy. Journal of Strategic Marketing, 1-17.

[46] Qi, X., \& Ploeger, A. (2019). Explaining consumers' intentions towards purchasing green food in Qingdao, China: The amendment and extension of the theory of planned behavior. Appetite, 133, 414422.

[47] Rana, J., \& Paul, J. (2017). Consumer behavior and purchase intention for organic food: A review and research agenda. Journal of Retailing and Consumer Services, 38, 157-165.

[48] Roddy, G., Cowan, C. A., \& Hutchinson, G. (1996). Consumer attitudes and behaviour to organic foods in Ireland. Journal of International Consumer Marketing, 9(2), 41-63.

[49] Saleki, R., Quoquab, F., \& Mohammad, J. (2019). What drives Malaysian consumers' organic food purchase intention? The role of moral norm, self-identity, environmental concern and price consciousness. Journal of Agribusiness in Developing and Emerging Economies.

[50] Scalco, A., Noventa, S., Sartori, R., \& Ceschi, A. (2017). Predicting organic food consumption: A meta-analytic structural equation model based on the theory of planned behavior. Appetite, 112, 235248.

[51] Shafie, F. A., \& Rennie, D. (2012). Consumer perceptions towards organic food. Procedia-Social and Behavioral Sciences, 49, 360367.

[52] [52] Shaheen, M. A.-R., El-Nakhlawy, F. S., \& Al-Shareef, A. R. (2013). Main factors influencing the spread and consumption of organic food in Saudi Arabia. Journal of Food, Agriculture \& Environment, 11(1), 231-233.
[53] Singh, A., \& Verma, P. (2017). Factors influencing Indian consumers' actual buying behaviour towards organic food products. Journal of cleaner production, 167, 473-483.

[54] Smith, S., \& Paladino, A. (2010). Eating clean and green? Investigating consumer motivations towards the purchase of organic food. Australasian Marketing Journal (AMJ), 18(2), 93-104.

[55] Stobbelaar, D. J., Casimir, G., Borghuis, J., Marks, I., Meijer, L., \& Zebeda, S. (2007). Adolescents' attitudes towards organic food: a survey of 15-to 16-year old school children. International journal of consumer studies, 31(4), 349-356.

[56] Suciu, N. A., Ferrari, F., \& Trevisan, M. (2018). Organic and conventional food: Comparison and future research. Trends in Food Science \& Technology.

[57] Suciu, N. A., Ferrari, F., \& Trevisan, M. (2019). Organic and conventional food: Comparison and future research. Trends in Food Science \& Technology, 84, 49-51.

[58] Tandon, A., Dhir, A., Kaur, P., Kushwah, S., \& Salo, J. (2020). Why do people buy organic food? The moderating role of environmental concerns and trust. Journal of Retailing and Consumer Services, 57, 102247

[59] Teng, C.-C., \& Lu, C.-H. (2016). Organic food consumption in Taiwan: Motives, involvement, and purchase intention under the moderating role of uncertainty. Appetite, 105, 95-105.

[60] Teng, C.-C., \& Wang, Y.-M. (2015). Decisional factors driving organic food consumption. British food journal.

[61] Testa, F., Sarti, S., \& Frey, M. (2019). Are green consumers really green? Exploring the factors behind the actual consumption of organic food products. Business Strategy and the Environment, 28(2), 327-338

[62] Ueasangkomsate, P., \& Santiteerakul, S. (2016). A study of consumers' attitudes and intention to buy organic foods for sustainability. Procedia Environmental Sciences, 34, 423-430.

[63] Van Huy, L., Chi, M. T. T., Lobo, A., Nguyen, N., \& Long, P. H. (2019). Effective segmentation of organic food consumers in Vietnam using food-related lifestyles. Sustainability, 11(5), 1237.

[64] Van Loo, E. J., Alali, W., \& Ricke, S. C. (2012). Food safety and organic meats. Annual review of food science and technology, 3, 203-225.

[65] Voon, J. P., Ngui, K. S., \& Agrawal, A. (2011). Determinants of willingness to purchase organic food: An exploratory study using structural equation modeling. International Food and Agribusiness Management Review, 14(2), 103-120.

[66] Wang, X., Pacho, F., Liu, J., \& Kajungiro, R. (2019). Factors influencing organic food purchase intention in developing countries and the moderating role of knowledge. Sustainability, 11(1), 209

[67] Xie, B., Wang, L., Yang, H., Wang, Y., \& Zhang, M. (2015). Consumer perceptions and attitudes of organic food products in Eastern China. British food journal.

[68] Yin, S., Wu, L., Du, L., \& Chen, M. (2010). Consumers' purchase intention of organic food in China. Journal of the Science of Food and Agriculture, 90(8), 1361-1367.

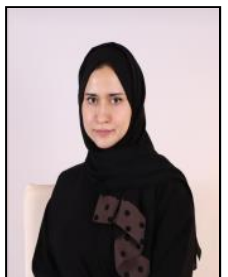

Dr. Eman Alshammari holds a bachelor's degree in business administration from King Saud University in Saudi Arabia, and a master's degree in business administration from Shenandoah University in the United States. Dr. Alshammari also hold a $\mathrm{PhD}$ in marketing from Swansea University in the United Kingdom. She is a licensed management trainer by Technical and Vocational Training Corporation in Saudi Arabia. She is currently an assistant professor of marketing at the College of Economics and Administrative Sciences, at Imam Muhammad ibn Saud Islamic University. Nine years of solid experience in the field of higher education including wide experience in teaching marketing, leadership and management courses. Dr. Alshammari research and teaching revolve around the themes of consumer behavior, international marketing and modern marketing. 